\title{
Relationship between Prevalence of Overweight and Obesity in Adolescent Girls, and Socio- Economic Status of their Families: A case study in Tehran
}

\begin{abstract}
Keywords: Adolescent girls; Overweight; Obesity; Socio-economic condition of households

Abstract

Background: Obesity of adolescents is a complicated health problem which depends on several factors like obesity of parents, childhood era nutrition, socio-economic condition, and physical activity. Its main goal was to find the relationship between prevalence of overweight and obesity among adolescent girls in Northern and Southern of Tehran, and socio-economic status of their families.

Materials \& Methods: This study was a cross-sectional, descriptive and analytical. In this study, 105 high-school adolescent girls from Northern part (with high socio-economic status) and 105 from Southern part (with low socio-economic status) of Tehran were selected through simple-randomized, two-step cluster sampling. The socio-economic information including education level and employment status of the samples' parents were collected using a self-administration questionnaire. Weight and height of the samples were measured according to the standard method. For measuring "Body Mass Index" (BMI) of the samples, the reference of CDC (center for Disease Contro and Prevention-CDC 2000; USA) was used.

Results: Prevalence of over-weight and obesity was $15.2 \%$ and $26.7 \%$ among the adolescent girls of Northern and Southern parts of Tehran, respectively $(P=0.04)$. The results showed that there was a significant statistical relationship between the mean of Northern part girls' BMI and education level of their mothers ( $P=0.04)$, and also between overweight and obesity of Southern part girls and education level of their mothers $(\mathrm{P}<0.05)$. Therefore, paying more attention to adolescents in educational and interventional programs of nutrition and health status improvement is necessary.
\end{abstract}

\section{Introduction}

Adolescents comprise a main part of population in most countries. According to the results of the census of 2011, 15-19 year old age group comprises $8.79 \%$ of Iran's population [1]. In such a young country, proper programming based on preventive health is too important. According to the estimation of CDC in 20112012, prevalence of obesity among adolescents aged 12-19 year old were $20.5 \%$ in the United States [2]. Prevalence of overweight and obesity among Iranian girls aged 15 to 19 years was $10.2 \%$ and $3.7 \%$, respectively [3]. Prevalence of overweight in Iranian high school students was $11.2 \%$ in 2004 [4].

Obesity of children and adolescents is a complicated health problem which depends on several factors like obesity of parents, childhood era nutrition, socio-economic condition, and physical activity [5]. Overweight and obesity in adolescence increase the probability of the incidence of metabolic disorders in future years,

\section{Journal of}

Nutrition and Health

\section{Mitra Abtahi ${ }^{1 *}$, Hamed Pouraram² ${ }^{2}$ Abolghasem Djazayeri², Mohammad Reza Eshraghian ${ }^{3}$ and Maryam Amini'}

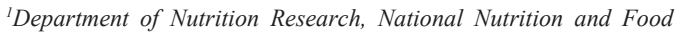
Technology Research Institute, Faculty of Nutrition and Food Technology, Shahid Beheshti University of Medical Sciences, Tehran, Iran

${ }^{2}$ Department of Community Nutrition, School of Nutritional Sciences and Dietetics, Tehran University of Medical Sciences (TUMS), Tehran, Iran

${ }^{3}$ School of public Health and Institute of Public Health Research, Tehran University of Medical Sciences, Tehran, Iran

\section{*Address for Correspondence}

MitraAbtahi, Department of Nutrition Research, National Nutrition and Food Technology Research Institute, Faculty of Nutrition and Food Technology, Shahid Beheshti University of Medical Sciences, Tehran 19395-4741, Iran, Tel : +98 (21) 22357486; Fax: +98 (21) 2236 0660; E-mail: mitra_abtahi@ yahoo.com

\section{Submission: 19 September, 2015}

Accepted: 12 January, 2016

Published: 18 January, 2016

Copyright: (๑ 2016 Abtahi M, et al. This is an open access article distributed under the Creative Commons Attribution License, which permits unrestricted use, distribution, and reproduction in any medium, provided the original work is properly cited.

independent to the obesity in adulthood [6,7]. In Iran, there is not any national report on the prevalence of Overweight and obesity in adolescence, and existing statistics have been gained from the scattered studies in this issue. In a study, the prevalence of overweight and obesity of Tehran's adolescent girls was estimated at $21.3 \%$ [8]. In another study, the prevalence of over-weight and obesity of 18 year old girls of division 13 of Tehran was reported as $13.3 \%$ [9]. On the other hand, the prevalence of obesity among 6-18 year old students of the "kingdom of Saudi Arabic" (KSA), one of the member states of EMRO-WHO, was estimated at $15.8 \%$ [10]. It seems that the main reason of this issue is the change of the pattern of food consumption, especially consuming more high-fat foods [11].

Health is affected by socio-economic status. Income, profession and education level of parents are widely used as the indicators of socio-economic status [12]. Recognizing the risk factors of obesity of adolescents can help in developing the proper approaches for preventing this problem. The low socio-economic status is one of those risk factors. It has been shown that there is a relationship between the low socio-economic status and incidence of obesity at both adolescence and adulthood [13]. The results of a study in USA showed that there is a high prevalence of overweight among the children of low-income families. So, the socio-economic status is one of the most important factors which should be addressed in obesity reducing programs in low socio-economic communities [14].

The goal of this study was to find the probable relationship between the prevalence of overweight and obesity of the adolescent girls of Northern and Southern parts of Tehran, and the socioeconomic status of their families. In this study, the adolescent girls of 
Citation: Abtahi M, Pouraram H, Djazayeri A, Eshraghian MR, Amini M. Relationship between Prevalence of Overweight and Obesity in Adolescent Girls, and Socio-Economic Status of their Families: A case study in Tehran. J Nutri Health. 2016;2(1): 4.

division 1 of Tehran city (Northern of Tehran) who live in relatively high socio- economic status families were compared to their counterparts in division 19 of Tehran city (Southern of Tehran) who live in relatively low socio-economic families. It is hoped that the results of this study can help in designing and implementing the appropriate programs on improving the health status of the adolescents of the country.

\section{Materials and Methods}

This is a descriptive-analytical, cross sectional research study in which the food consumption patterns of the adolescent girls of Northern and Southern parts of Tehran have been compared.

Statistical samples of this study include student girls of grades one to three of public sector high-schools, from division 1 (with high socio-economic status) and division 19 (with low socio-economic status) of Tehran. The samples were selected through a two-step cluster sampling. The clusters were selected systematically, and in each cluster, the samples were selected randomly. Systematic sampling was considered for selecting the clusters, regarding to the scores of high-schools and the number of students of each grade. For each grade, for each division, 105, and totally 210 samples were considered for this study. Samples out of the pre-defined age range of this study (14-17 years) were excluded and new samples were randomly included instead. The students which were on weight-loss diet were excluded too. All of the samples provided written consents for entering the study. At the beginning of study, the questionnaire of socio-economic information was completed for all of the samples. The socio-economic status of the samples was indirectly assessed, using variables of parents' education level and parents' occupation situation [15].

The weights were measured in light clothing, using digital Seca scales with $0.1 \mathrm{~kg}$ precision. Each student was weighed twice, and the average of two measures was recorded as the final weight. The scales were calibrated every day with a control $5 \mathrm{~kg}$ stone, before starting the weight measurement. The heights were measured in bare feet, using non-elastic tape-meters with $0.1 \mathrm{~cm}$ precision, while the samples' knees, hip, shoulders and head-back were in a straight line, and arms were free at the sides of body. Body Mass Index (BMI) of the samples was calculated through dividing their body weight $(\mathrm{kg})$ by their height $(\mathrm{cm})$ square. The normal weight and overweight of samples were considered as $15^{\text {th }}$ percentile $<\mathrm{BMI}<85^{\text {th }}$ percentile and $\mathrm{BMI} \geq 85^{\text {th }}$ percentile (CDC; 2000 ), respectively $[10,16]$.

The qualitative variables of the two study parts of Tehran were compared using Fischer and Chi-Square tests. Independent $t$ test and one-way variance analysis test were used for comparing the means, and finding relationship between quantitative and qualitative variables, respectively. $\alpha=0.05$ was considered as the cut-off of significance. Statistical data processing was done using SPSS software, version 11.5.

\section{Results}

The findings of this study showed that according to the $\mathrm{BMI} \geq 85^{\text {th }}$ percentile $15.2 \%$ (95\% of confidence Interval: $8.5-22.8$ ) and $26.7 \%$ (95\% of confidence Interval: 18.6-36.2) of the Northern and southern parts girls of Tehran had overweight, respectively. Chi-Square test showed that the percent of overweight/obese girls of the southern was significantly more than the girls of the Northern $(\mathrm{P}=0.04)$.

Table 1 shows the anthropometric specifications of the studied students. The means of the BMIs of the Northern and Southern parts girls of Tehran were $21.5 \pm 3 \mathrm{~kg} / \mathrm{m}^{2}$ and $22.7 \pm 5.8 \mathrm{~kg} / \mathrm{m}^{2}$, respectively. The independent $\mathrm{t}$ test showed that the means of the BMIs of Northern and Southern parts girls of Tehran were significantly different $(\mathrm{P}=0.04)$.

Findings of socio-economic status of the studied students, including their parents' education level and occupation, showed that in Northern and Southern parts of Tehran, fathers with B. Sc degree and higher (43.6\%), and with pre-high school degree (35.2\%), have the highest percentage, respectively. Also, in North, nearly $90 \%$ of fathers had a job, while in South, just about $80 \%$ of fathers had a job and almost $5.8 \%$ of them were jobless. The highest percentage of mothers, education group in Northern and Southern parts of Tehran were high-school level (48.6\%) and pre-high school level (33.3\%), respectively. In Northern, about $26 \%$ of mothers had a job, while in South; about $97 \%$ of mothers were housewives. According to Fischer and chi-score tests, the high-school girls of Northern and Southern parts of Tehran were significantly different regarding their parents' education and occupation $(\mathrm{P}<0.0001)$. The results show that these indicators indicate the socio-economic conditions.

One-way variance analysis test showed a significant relationship between BMI of the Northern girls, and education level of their mothers $(\mathrm{P}=0.04)$. There wasn't such a relationship in the Southern. Not any significant relationship was seen between BMI of the studied girls and education level of their fathers, in both two parts of Tehran.

In the Southern, $89.3 \%$ and $10.7 \%$ of the mothers of overweight/ obese girls were housewives and employed, respectively. There was a significant relationship between overweight and obesity of the studied girls, and employment of their mothers, in the low socio-economic part $(\mathrm{P}<0.05)$ (Table 2).

\section{Discussion and Conclusion}

The goal of this study was to find the probable relationship between overweight and obesity of the Northern and Southern parts adolescent girls, and socio-economic status of their families. The results showed the high prevalence of overweight and obesity among the girls with low socio-economic status. According to the standard of CDC 2000 which defines $\mathrm{BMI} \geq 85^{\text {th }}$ percentile as overweight or obesity, $15.2 \%$ and $26.7 \%$ of the adolescent girls of Northern and Southern parts of Tehran had overweight or obesity.

The prevalence of overweight and obesity among the adolescent girls of the Northern of Tehran was similar to the reported amounts

Table 1: Anthropometric data of high school adolescent girls in Tehran, 2006.

\begin{tabular}{|c|c|c|c|}
\hline $\begin{array}{c}\text { Area } \\
\text { Variables }\end{array}$ & $\begin{array}{c}\text { North(n=105) } \\
\text { Mean } \pm \text { SD }\end{array}$ & $\begin{array}{c}\text { South(n=105) } \\
\text { Mean } \pm \text { SD }\end{array}$ & t-test \\
\hline Weight (kg) & $55.2 \pm 8.9$ & $55.4 \pm 10.0$ & NS \\
\hline Height (cm) & $160.0 \pm 5.4$ & $157.8 \pm 5.0$ & 0.002 \\
\hline BMI (kg/m2) & $21.5 \pm 3.0$ & $22.7 \pm 5.8$ & 0.04 \\
\hline
\end{tabular}


Citation: Abtahi M, Pouraram H, Djazayeri A, Eshraghian MR, Amini M. Relationship between Prevalence of Overweight and Obesity in Adolescent Girls, and Socio-Economic Status of their Families: A case study in Tehran. J Nutri Health. 2016;2(1): 4.

Table 2: Parents' occupation of high school adolescent girls in Tehran based on weight status, 2006.

\begin{tabular}{|c|c|c|c|c|c|c|c|}
\hline \multirow[t]{2}{*}{ Area } & \multirow[b]{2}{*}{ Weight status } & \multicolumn{2}{|c|}{ North $(n=105)$} & \multirow[b]{2}{*}{ Fisher's Test } & \multirow{2}{*}{$\begin{array}{c}\text { South(n=105) } \\
\text { Overweight/ } \\
\text { obese } \\
n(\%)\end{array}$} & \multirow[b]{2}{*}{$\begin{array}{c}\text { Normal } \\
n(\%)\end{array}$} & \multirow[b]{2}{*}{ Fisher's Test } \\
\hline & & $\begin{array}{l}\text { Overweight/ } \\
\text { obese } \\
n(\%)\end{array}$ & $\begin{array}{c}\text { Normal } \\
\mathrm{n}(\%)\end{array}$ & & & & \\
\hline & Employed & 13(81.2) & $81(91.0)$ & & $21(75.0)$ & $63(81.8)$ & \\
\hline \multirow[t]{2}{*}{ Father's job } & Unemployed & $0(0)$ & $0(0)$ & & $1(3.6)$ & $4(5.2)$ & NS \\
\hline & Retired & $3(18.8)$ & $8(9.0)$ & NS & $6(21.4)$ & $10(13.2)$ & \\
\hline \multirow[t]{2}{*}{ Mother's job } & Housewife & $11(68.8)$ & $67(75.3)$ & NS & $25(89.3)$ & $76(98.7)$ & \\
\hline & Employed & $5(31.2)$ & $22(24.7)$ & & $3(10.7)$ & $1(1.3)$ & $P<0.05$ \\
\hline
\end{tabular}

from Tehran girls [17-19], as well as the high-school girls from Semnan, Hamedan and Tabriz cities [20-22]. The coincident prevalence amount of overweight and obesity among the girls of the Southern of Tehran was more than the reported amounts from the adolescent girls of divisions 13 and 16 of Tehran city [17,23].

About the prevalence of overweight and obesity among the adolescent girls of Northern and Southern parts of Tehran, it can be concluded that the prevalence of overweight and obesity among the adolescent girls from high socio-economic families, is similar to the reported amounts from the other parts of Tehran and other cities of the country, with similar socio-economic level. The difference between the prevalence of overweight and obesity of the adolescent girls from south parts with relatively similar socio-economic status is probably due to the happened change in food pattern and life style of urban communities during the past decade. It seems that overweight and obesity have a considerable effect on the people with low socioeconomic status, although the main reasons of the relationship between obesity and socio-economic status are food habits and life style. So, since overweight and obesity is relatively prevalent among the adolescent girls of Tehran, especially those with low socioeconomic level, adopting urgent actions for reversing this trend and preventing its individual and social complications is crucial.

In this study, the mean of BMIs of the adolescent girls from Northern and Southern parts of Tehran were 21.5 and $22.7 \mathrm{~kg} / \mathrm{m}^{2}$, respectively. These figures are similar to the reported amounts from the adolescent girls of division 6 of Tehran and Lahijan city [24,25].

In this study, the mean of BMI of the girls from the Southern of Tehran was more than the girls from the Northern. This, in fact, shows the higher prevalence of obesity among the girls from families with low socio-economic status. There was also a significant difference between the mean of BMIs of the girls from the two studied parts of Tehran. The results of a study on 11-18 year old adolescents in Isfahan showed the higher prevalence of overweight and obesity among the adolescents who had mothers with low education level, or families with how socio-economic status [26].

According to the findings of this study, there was a significant difference between the socio-economic status of high-school adolescent girls from the two studied parts, including their parents' education level and employment. In the north part of Tehran, there was just a significant difference between the mean of BMI of the studied girls and the education level of their mothers. The results of a study on the high school girls of Tehran in 2002 showed a significant statistical relationship between the education level of mothers and the percentile of BMI of adolescent girls and education level of their parents in a study in the United States [13], and between BMI and socio-economic status in a study in Australia [27]. This is probably due to the fact that studied populations were adolescents whose nutritional information and behavior is affected by their parents.

In the Southern of Tehran, there was just a significant relationship between overweight and obesity of the samples, and employment of their mothers, and there wasn't any relationship between overweight and obesity of the girls, and education level of their parents. Not any relationship was also reported between BMI of the adolescent girls and the education level of their parents, in a study which was done in divisions 2 and 7 of Tehran [28]. No relationship was seen between BMI of the adolescent girls and their socio-economic status, in a study in India too [29]. In a study on the Chinese girls, there wasn't any significant statistical relationship between overweight and obesity of adolescents, and education level and employment of their parents [30]. This can be mainly due to the low level of the parents' education, and inadequate information interchange among the family members.

Totally, it can be concluded from the results of this study that overweight and obesity were serious health problem among the adolescent girls of Tehran, especially in low socio-economic parts. Education level and employment of mothers (as the managers of households) were among the most important obesity related socioeconomic factors. In this study since the education level of mothers was associated with the nutritional status of family members, improving their nutritional literacy and providing nutrition education for them may control obesity among adolescents. Therefore, paying attention to the adolescents, especially those who live in low-income areas, in educational and interventional programs of improving nutrition and health level of individuals and communities, can be regarded as a prioritized necessity.

\section{References}

1. (1996) National Planning and management organization: population based on sex and age group. Nat Anniversary Statistic, pp. 54-1380.

2. http://www.cdc.gov/obesity/data/childhood.html

3. Mohammadpour Ahranjani B, Abdollahi M, Houshiarrad A (2006) Overweight and obesity in the Iranian population, 2001. Iran J Nutr 2: 53

4. Kelishadi R (2007) Childhood overweight, obesity, and the metabolic syndrome in developing countries. Epidemiol Rev 29: 62-76.

5. McCarthy HD, Ellis SM, Cole TJ (2003) Central overweight and obesity in British youth aged 11-16 years: Cross sectional surveys of waist circumference. Brit Med J 326: 626-628. 
Citation: Abtahi M, Pouraram H, Djazayeri A, Eshraghian MR, Amini M. Relationship between Prevalence of Overweight and Obesity in Adolescent Girls, and Socio-Economic Status of their Families: A case study in Tehran. J Nutri Health. 2016;2(1): 4.

6. Power C, Lake JK, Cole TJ (1997) Measurement and long-term health risks of child and adolescent fatness. Int J Obes Relat Metab Disord 21: 507-526.

7. Haas JS, Lee LB, Kaplan CP, Sonneborn D, Phillins KA, et al. (2003) The association of race, socioeconomic status, and health insurance status on the prevalence of overweight among children and adolescents. Am J Public Health 93: 2105-2110.

8. Mohammadpour-Ahranjani B, Rashidi A, Karandish M, Eshraghian MR kalantari N (2004) Prevalence of overweight and obesity in adolescent Tehrani students, 2000-2001: an epidemic health problem. Public Health Nutr 5: 645-648.

9. Mirmiran P, Mohammadi F, Allahverdian S, Azizi F (2000) Prevalence of underweight and overweight among adolescents: Tehran Lipid and Glucose Study. $6^{\text {th }}$ congress of Nutrition.

10. World Health Organization (2000) Obesity: preventing and managing the global epidemic. Report of WHO Consultation. Geneva, pp: 9-32

11. Feunekes GI, de Graf C, Meyboom S, van Staveren WA (1998) Food choice and fat intake of adolescents and adults: Associations of intakes within social networks. Prevent Med 27: 645-659.

12. Mishra G, Ball K, Arbuckle J, Crawford D (2002) Dietary patterns of Australian adults and their association with socioeconomic status: results from the 1995 National Nutrition Survey. Eur J Clin Nutr 56: 687-693.

13. Goodman E, Adler NE, Daniels SR, Morrison JA, Slap GB, et al. (2003) Impact of objective and subjective social status on obesity in a biracial cohort of adolescents. Obes Res 11: 1018-1026.

14. Mei Z, Scanlon KS, Grummer-Strawn LM, Freedman DS, Yip R, et al. (1998) Increasing prevalence of overweight among US low-income preschool children: The Center for Disease Control and prevention pediatric nutrition surveillance, 1983 to 1995 . Pediatrics 101.

15. Doustmohammadian A, Abdollahi M, Bondarianzadeh D, Houshiarrad A Abtahi M (2012) Parental determinants of overweight and obesity in Iranian adolescents: a national study. Iran J Pediatr 22: 35-42.

16. (2004) CDC: Center for Disease Control.

17. Pourmoghim M (1995) Assessment and comparison of nutritional status among female high school adolescents in two district north and south of Tehran. MSPH in Nutrition Thesis, Faculty of Health, Tehran University of medical sciences, pp. 1374.

18. Omidvar N (2002) Psychosocial factors determining food choice and nutritional status of high school adolescents of Tehran.

19. Arabshahi S (1997) Assessment and comparison of nutritional status among female adolescents 11-14 years old in districts of 6 and of Tehran.

20. Doustmohammadian A, Keshavarz A, Dorosti AR, Mahmodi M, Sadrzadeh $\mathrm{H}$ (2005) Survey of the nutritional status and relationship between physical activity and nutritional attitude with index of BMI-for-age in Semnan girl secondary school, Winter and Spring, 2004. Koomesh J 6: 187-194.

21. Seyf $Z$ (2004) Prevalence of obesity among adolescent girl in Hamedan. $8^{\text {th }}$ Iranian Nutrition Congress.

22. EzadifardSh, EghtesadiSh, Omidvar N, Ghodsi D (2004) Assessment of overweight and obesity and some nutritional factors among adolescents girl in Tabriz, $8^{\text {th }}$ Iranian Congress of Nutrition, Tehran, Iran.

23. Mirmiran P, Mirboloki MR, Mohammadi F, Azizi F (2003) Prevalence of Underweight and overweight among adolescents: Tehran Lipid and Glucose Study. Iranian J Endocrinol Metab Endocrine Res Center 377-371.

24. Dadkhah M, Omidvar N, Mehrabi Y (2006) Comparison of the fat intake patterns of female high school adolescents and their parents. J Nutri Sci Food Tech 1: 25-32.

25. Bazhan M (2001) Prevalence of obesity, fat distribution and association with food intake pattern of female high school in Lahijan city.

26. Kelishadi R, Pour MH, Sarraf-Zadegan N, Sadry GH, Ansari R, et al. (2003) Obesity and associated modifiable environmental factors in Iranian adolescents: Isfahan Healthy Heart Program-Heart Health Promotion from Childhood. Pediatr Int 45: 435-442.

27. Booth ML, Macaskill P, Lazarus R, Baur LA (1999) Sociodemographic distribution of measures of body fatness among children and adolescents in New South Wales, Australia. Int J Obes Relat Metab Disord 23: 456-462.

28. Esfarjani F, Vaziri B, Heidari H (2000) Assessment of food intake pattern among female adolescent in south of Tehran (Salehabad). Abstract Culture of food and drug consumption, Sari 79: 232.

29. Singh N, Mishra CP (2001) Nutritional status of adolescent girls of a slum community of Varanasi. Indian J Public Health 45:128-134.

30. Shi Z, Lien N, Kumar BN, Dalen I, Holmbose-Ottesen G (2005) The sociodemographic correlates of nutritional status of school adolescent in Jiangsu Province, China. J Adolesc Health 37: 313-322.

\section{Acknowledgement}

Thank you for the students of divisions 1 and 19 of Tehran for their kind part participation in this study. 